\title{
Render reinforced with textile threads
}

$$
\text { Jorge Pinto }{ }^{1,2} \text {, Artur Peixoto }{ }^{1} \text {, José Vieira }{ }^{1} \text {, Lisete Fernandes }{ }^{3} \text {, José Morais }{ }^{1} \text {, }
$$
Vítor M.C.F. Cunha ${ }^{1,4}$, Humberto Varum ${ }^{5}$

${ }^{1}$ Engineering Department, School of Science and Technology, University of Trás-osMontes e Alto Douro, Vila Real, Portugal

2 I3N, University of Aveiro, Campus Universitário de Santiago, 3810-193 Aveiro, Portugal

${ }^{3}$ Microscopy Unit, University of Trás-os-Montes e Alto Douro, Vila Real, Portugal

${ }^{4}$ ISISE, Institute for Sustainability and Innovation in Structural Engineering, University of Minho, Guimarães, Portugal

${ }^{5}$ Civil Engineering Department, University of Aveiro, Campus Universitário de Santiago, 3810-193 Aveiro, Portugal

\section{ABSTRACT}

From a sustainable technical building perspective, this research work aims to investigate the potential of using waste products of the textile industry in building applications. In particular, textile threads as an alternative fiber reinforcement solution for cement based coating mortar. Unfortunately, undesirable and unexpected shrinkage cracking coating mortar is still a relevant concern in the building industry. Taking into account that this building pathology has a huge disproportionate depreciative impact on the overall value of a property, it is important to find building solutions that may contribute to mitigate this technical problem. Meanwhile, finding applications for the waste derived from the textile industry may also result in attractive economical and sustainable solutions. Pieces of fabrics or pieces of textile threads are the most common types of waste resulting from this industry. A 70\% cotton and 30\% acrylic composition thread was the textile waste considered as a reinforcement fiber in this paper. A preliminary characterization of this composite material was experimentally performed. A parametric study including different fiber sizes, fiber contents and ages of the reinforced coating mortar was carried out. The applicability, the durability and the mechanical behaviour of the proposed reinforced mortar were the main material properties studied in this research work. The obtained experimental results indicate that the studied composite 
material may be interesting from technological, sustainable and economical points of views.

Keywords: Textile waste, fiber, coating mortar, reinforcement, sustainability

\section{1 - INTRODUCTION}

Reducing energy consumption, water consumption and $\mathrm{CO}_{2}$ emission to the atmosphere, without compromising the overall quality of a product, must be a goal to achieve in a production management system. Affordability is another extremely important parameter to take into account. Reusing, opting for green building materials (which must be renewable, local and abundant), retrofitting, choosing low technology production methods and techniques are some practices that have given good results within this context.

In the building industry context, it is extremely important to achieve such practices. Therefore, recent different research works have been done in order to find alternative sustainable building solutions. Using different agricultural product wastes [1-4] and other types of residues such as newspaper [5-6] or micro-cellulose fibers resulting from the recycling of cardboard of resinous origin [7] are some practical examples in which a waste product is used as a raw material in a production process of a building product. Textile waste has also been researched for this purpose [8-9]. From both sustainable and affordable construction points of view, the use of natural fibers to reinforce cement based materials may also be a feasible alternative to decrease the brittleness of mortars. Plant fibers have been used such as eucalyptus pulp, coir or eucalyptus [10], sisal [11] and kenaf (i.e. hibiscus cannabinus) [12].

In this research work, the building scenario of using waste of the textile industry as a fiber for reinforcing cement based coating mortar is put into perspective. Taking into account the expressive variability of types concerning this kind of waste, a $70 \%$ cotton and $30 \%$ acrylic composition thread was the textile waste selected and considered as fiber in this work. In general, the textile industry waste may be pieces of fabrics or pieces of textile threads. In both cases, the size, the composition (e.g. cotton, wool, 
acrylic, silk, linen, among other possible materials and mixtures) and the texture are some aspects that contribute to the above mentioned material variability. The complexity of studying this type of waste as a possible raw material in a production management system is proportional to this high material variability expectancy.

Prior to the study of the behavior of cement fiber reinforced composite, the textile thread characterization was performed. The microstructure of the fiber was characterized, then its tension strength capacity was assessed. Several reinforced coating mortar samples were processed in order to include two different lengths of fiber (e.g. 2 $\mathrm{cm}$ and $4 \mathrm{~cm}$ ) and five different fiber contents (e.g. $0 \%, 1 \%, 2 \%, 3 \%$ and $4 \%$ ). The traditional coating mortar corresponds the unreinforced mortar (i.e. 0\% fiber content) incorporated and it works as a reference mortar. In order to figure out the applicability of these proposed reinforced coating mortars, an experimental expedite procedure was done, which consisted on applying each solution on an external brick masonry wall. This preliminary experimental procedure was extremely valuable because it enabled the confirmation that each solution can to be applied on masonry walls. This fact was justified by the acceptable adhesion and the adequate scattering showed by all the samples. This experimental procedure also allowed the monitoring of the material behaviour of those samples under real extreme climate conditions during six consecutive months (from July 2011 to February 2012). In parallel, samples were also processed for bending and compressive tests.

Shrinkage and cracking of cement based coating mortars due to temperature amplitude is still a common building pathology, which tends to reduce the value of the real estate. Bad quality of materials (e.g. binders, aggregates and water), inadequate material proportions (e.g. poor amount of cement or high water content), inadmissible technical errors (e.g. high layer thickness or insufficient curing time), bad weather conditions during application (e.g. extreme dry or freezing conditions) and lack of information in the design are some causes of this type of building pathology. Usually, the related repairing procedures are complex and slow and, therefore, costly. One solution to mitigate this building problem, in particular the shrinkage cracking of coating mortars, consists on reinforcing the mortars. Different and well established reinforcement solutions have already been tested and made available in the building industry. Glass fiber net and metal net are some examples of these solutions. Meanwhile, alternative 
sustainable coating mortar reinforcement solutions have been proposed by the research community. For instance, acrylic fiber [13], recycled plastic fiber [14] and sisal fiber $[11,15]$ are among these possibilities. This paper intends precisely to give a contribution in this matter by proposing textile thread fiber.

This paper is structured as follows; firstly, the problematic of shrinkage cracking pathology of cement based coating mortars is briefly put into context; secondly, the proposed textile thread fiber is experimentally characterized. Its microstructure is identified and its tension strength is also evaluated; thirdly, a description of the sample preparation is delivered; fourthly, the experimental results are presented, analyzed and discussed; finally, the main conclusions are drawn.

\section{2 - CONTEXT}

As stated above, the problematic of shrinkage cracking of cement based coating mortars deeply concerns the building industry agents. This flaw results in a disproportionate depreciative impact on a building. In spite of not putting the overall stability of a construction at risk, it is easily noticed because it affects the façades and it may also contribute for a progressive occurrence of other building pathologies such as water infiltration and premature material degradation. Therefore, repairing building techniques are required to solve this problem. In general, apart from the repairing of the coating mortar itself, it is also necessary to fix the finishing of the façade. These repairing procedures end up being complex and costly. Thus, all the efforts to avoid the occurrence of this pathology must be done, which include rigorous control of the quality of the materials, specialized technicians, detailed design, among other constrains. Additionally, building scenarios in which the likelihood of the appearance of this defect is higher, may require additional preventive measures such as applying a reinforcement of the coating mortar. An example of this building pathology and a traditional reinforcement based on using a metal net are presented in Figure 1.a and 1.b, respectively. 


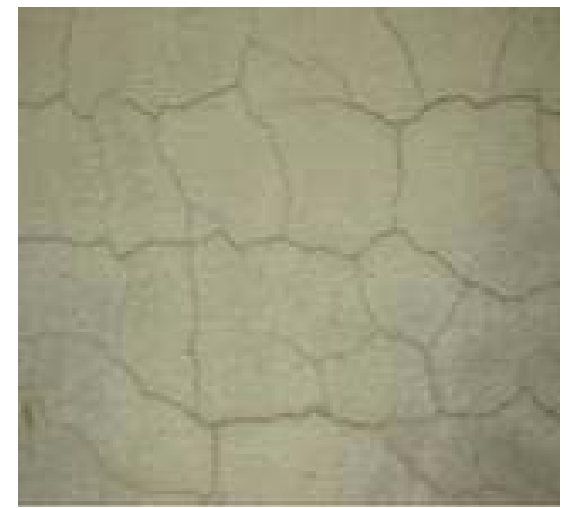

a) The building pathology

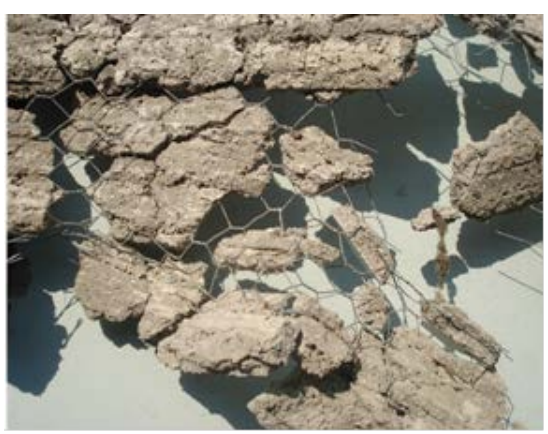

b) A traditional reinforcement

Figure 1: Examples of the pathology and of a reinforcement solution possibility

\section{3 - CHARACTERIZATION OF THE THREAD}

A $70 \%$ cotton and 30\% acrylic composition thread is considered here as a textile fiber reinforcing solution of coating mortar against shrinkage cracking, and as a sustainable and an economical alternative building solution. This thread is a textile industry waste. For instance, this type of fiber is intended as a substitute of the metal net of the traditional reinforcement solution presented in Figure 1.b. The considered thread and its microstructure are shown in Figure 2.a and 2.b. It is possible to realize that the thread is formed by a set of micro threads, Figure 2.b. The thread has a diameter equal to $1 \mathrm{~mm}$, approximately. Meanwhile, the average diameter of the micro threads is $17.75 \mu \mathrm{m}$, Figure 2.c.

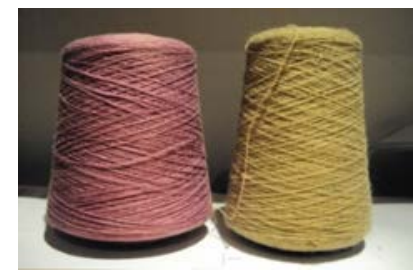

a) The thread

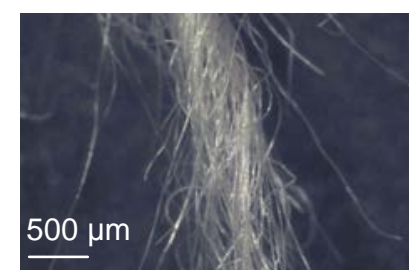

b) Microstructure

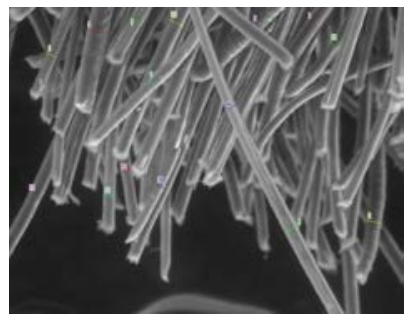

c) Micro thread

Figure 2: The considered textile thread

In order to evaluate the tensile strenght of the thread, ten thread samples were tested in terms of uniaxial tension. Each sample had $10 \mathrm{~cm}$ length. An Instron 5848 MicroTester machine was used to perform the tensile tests. These tests were carried out with a displacement ratio of $10 \mathrm{~mm} /$ minute. Figure 3 depicts the experimental tensile stress - 
strain curves. The average tensile strenght was 7.44 MPa with a coefficient of variation of 6.8\%. A 24.40 MPa modulus of elasticity was obtained. The material shows a linear elastic behaviour up to the peak followed by a sudden rupture.

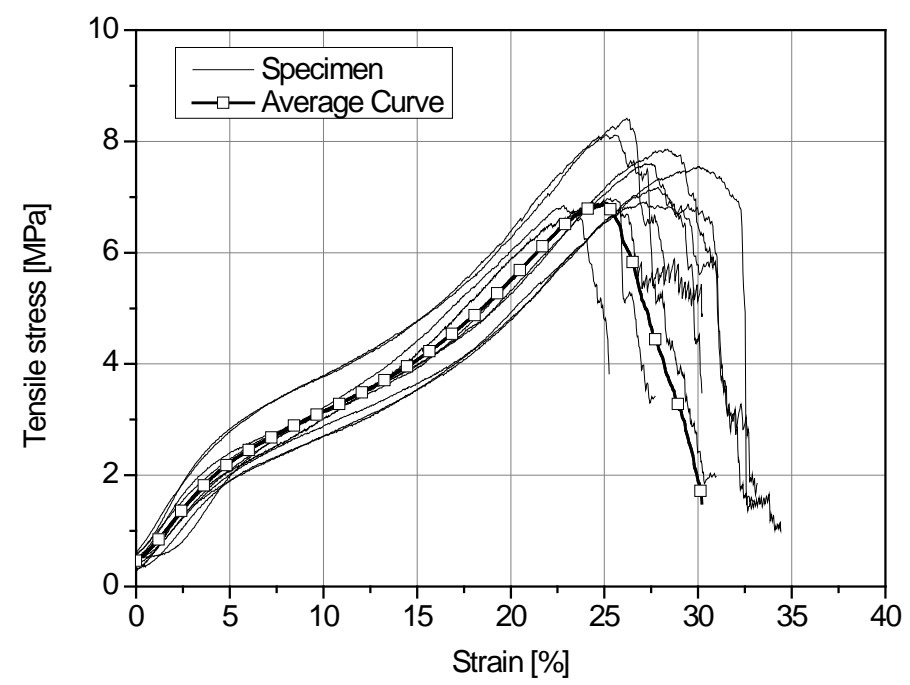

Figure 3: Tensile stress - strain curves

\section{4 - REINFORCED COATING MORTAR SAMPLE PREPARATION}

\section{1 - Mixture compositions}

As it was mentioned earlier, a parametric study was conducted in order to assess the mechanical behaviour improvement of a traditional coating mortar when textile thread fibers are incorporated. The fiber content to incorporate and the fiber length were the selected parameters to be analyzed. At this stage, four fiber contents, FC, (e.g. 1\%, 2\%, $3 \%$ and $4 \%$ ) and two fiber lengths (e.g. $2 \mathrm{~cm}$ and $4 \mathrm{~cm}$ ) were the parameters considered. Therefore, five different reinforced coating mortar compositions were prepared based on the typical volume ratio of 1:1:6 (i.e. cement (C):lime (L):sand (S)) commonly adopted in traditional cement based coating mortars. Each composition was related to a certain fiber content. For instance, the $1 \%$ fiber content composition corresponds to the ratio of 0.02:1:1:6 (i.e. fiber (F):cement (C):lime (L):sand (S)). A 70\% water (W)/binder (C and L) weight ratio was adopted in order to guarantee an adequate workability of the reinforced mortar, in particular, for the $4 \%$ fiber content case. It is worth to underline that the first composition is related to the traditional one in which there is no fiber incorporated (i.e. $0 \%$ content). A detailed presentation of this information is displayed 
Table 1: Reinforced coating mortar compositions

\begin{tabular}{|c|c|c|c|c|c|c|}
\hline Composition & FC (\%) & F (g) & C (g) & L (g) & S (g) & W (g) \\
\hline 1 & 0 & 0,0 & 710 & 710 & 4260 & 994 \\
\hline 2 & 1 & 14,2 & 710 & 710 & 4260 & 994 \\
\hline 3 & 2 & 28,4 & 710 & 710 & 4260 & 994 \\
\hline 4 & 3 & 42,6 & 710 & 710 & 4260 & 994 \\
\hline 5 & 4 & 56,8 & 710 & 710 & 4260 & 994 \\
\hline
\end{tabular}

\section{2 - Preliminary testing procedure}

165

Before testing the proposed reinforcement solutions in terms of bending and compression, a preliminary testing procedure was performed in order to evaluate the practical feasibility of applying this composite material as a coating mortar. In other words, it was important to evaluate the practicability of the reinforcement solutions in an early stage of this research. In general, the technical aspects of adherence to the support and the scattering are fundamental in the cement based coating mortar applicability performance context. Therefore, an $11 \mathrm{~cm}$ thickness brick masonry model was built outside in the north region of Portugal (Figure 4.a) and nine different cement based coating mortar samples (e.g. Case 1: fiber content $=0 \%$; Case 2 : fiber length $=2$ $\mathrm{cm}$ and fiber content $=1 \%$; Case 3: $2 \mathrm{~cm}$ and 2\%; Case 4: $2 \mathrm{~cm}$ and 3\%; Case 5: $2 \mathrm{~cm}$ and 4\%; Case 6: $4 \mathrm{~cm}$ and 1\%; Case 7: $4 \mathrm{~cm}$ and 2\%; Case 8: $4 \mathrm{~cm}$ and 3\%; Case 9: 4 $\mathrm{cm}$ and $4 \%$ ) were applied on the support (i.e. the brick masonry wall). These samples were approximately sized 0,01 $\mathrm{m} \times 0,8 \mathrm{~m} \times 0,6 \mathrm{~m}$ (i.e. thickness $\times$ width $\times$ height), Figure 4.a. This task started on $22^{\text {nd }}$ of July of 2011. It was verified that all the tested coating mortar samples showed an adequate workability performance. However, it was also concluded that the $4 \%$ content of incorporated fiber reduces the water content of the mixture and, therefore, it slightly decreases its workability. Furthermore, the samples that had $4 \mathrm{~cm}$ length fiber incorporated (Figure 4.b) required additional application care. This fact indicates that the workability of the reinforced mortar tends to decrease when the fiber length increases. On the other hand, this preliminary experimental procedure also made it possible to monitor the behavior of the reinforced 
solutions during six consecutive months (i.e. from $22^{\text {nd }}$ of July of 2011 to $22^{\text {nd }}$ of February of 2012). In this scenario, the samples were directly exposed to the natural weather conditions, which included exposure to severe temperatures (e.g. $40^{\circ} \mathrm{C}$ in August of 2011 and $-4^{\circ} \mathrm{C}$ in February of 2012). During this period of time, all the samples showed an adequate material performance because there was no visible shrinkage cracking appearance, the material kept its integrity, and there was no delamination from the masonry wall.

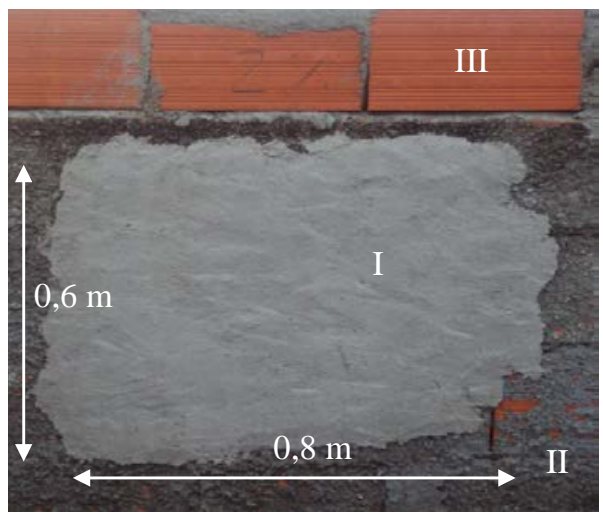

a) A coating mortar sample (February 2012) masonry wall

Figure 4: A mortar sample application and the $4 \mathrm{~cm}$ fiber thread

\section{5 - BENDING AND COMPRESSION BEHAVIORS}

\section{1 - Preliminary considerations}

Bending and compression tests were performed in order to evaluate the mechanical benefit resulting from the incorporation of the $70 \%$ cotton and $30 \%$ acrylic thread fiber. Therefore, reinforced coating mortar samples sized $0,04 \mathrm{~m} \times 0,04 \mathrm{~m} \times 0,16 \mathrm{~m}$ (i.e. width $\times$ height $\times$ length) were processed according to [16, 17], considering the compositions presented in Table 1, and using $2 \mathrm{~cm}$ and $4 \mathrm{~cm}$ fiber lengths separately. The evolution process of these mechanical properties during the curing time was also another technical aspect analyzed. Thus, the samples were tested at the ages of 14 days and 28 days. In order to achieve all these objectives, it was necessary to prepare 108 samples. Considering the procedure prescribed in [16], the curing process of the samples occurred as follows: Step 1 - during the first two days the samples were kept 
under the controlled thermo hygrometric conditions of the laboratory; Step 2 - during the subsequent five days the samples were put in a climatic chamber under a constant temperature of $65^{\circ} \mathrm{C}$; Step 3 - the samples were kept in the laboratory under t similar curing conditions as in Step 1, and until the testing date. In general, the density is an important physical property to assess in a characterization process of a material. In this research, the density was evaluated when the samples were aged 2 days, 14 days and 28 days, and in order to understand how this measure changed during the curing time. Taking into account the above described curing condition process, the density of the samples related to the cases from 1 to 10 tended to decrease according to the progress of the curing, and because of the associated evaporation progress of the retained water. It was verified that the density tends to increase slightly as fiber content increases. The length of the incorporated fiber does not seem to affect the density directly, no pattern was noticed. The evaluated densities also allow to state that there was an adequate material uniformity among the processed samples. The existing regular discrepancy is very likely to be related to the sample preparation. In order to complement this information, the average densities of the different cases, at 28 days, are presented in the diagram of Figure 5. For simplification sake, the respective diagrams for ages of 2 days and 14 days are not presented here.

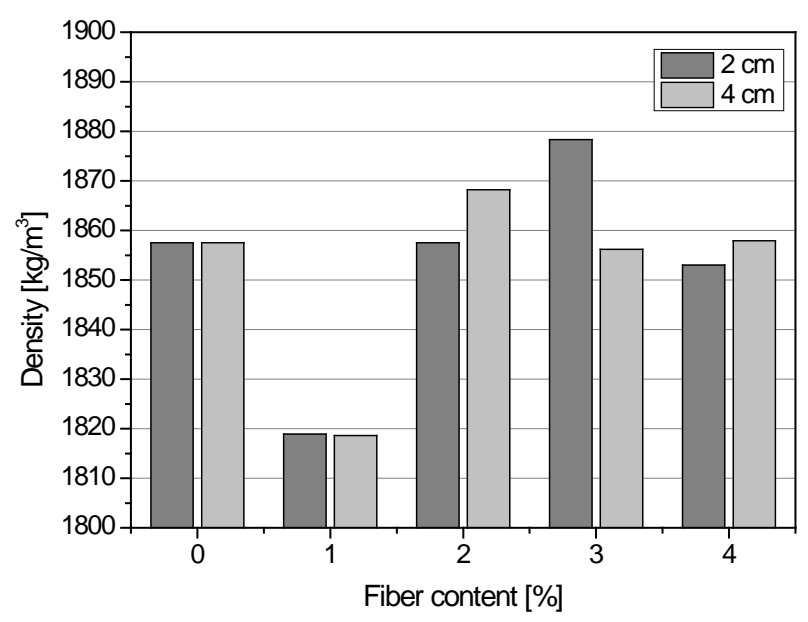

Figure 5: Average density at 28 days

\section{2 - Bending test}

A Seydner Mega 10/250/15D testing rig was used in the three-point bending test. The 
span was $100 \mathrm{~mm}$. The 108 cement based coating mortar samples related to the cases from 1 to 9 were tested at the ages of 14 days and 28 days. The evaluated ultimate bending stresses, $\sigma_{\mathrm{b} 14}$ and $\sigma_{\mathrm{b} 28}$, are presented in Figures 6 and 7 for these ages. The experimental results obtained indicate that the bending strength of the reinforced coating mortar tends to increase with the increase of the fiber content. There is no clear evidence that it is advantageous to use high lengths of fiber. Taking the adopted curing conditions into account, the main bending strength capacity was achieved before 14 days. From that age, there was only a residual strength capacity improvement with time.

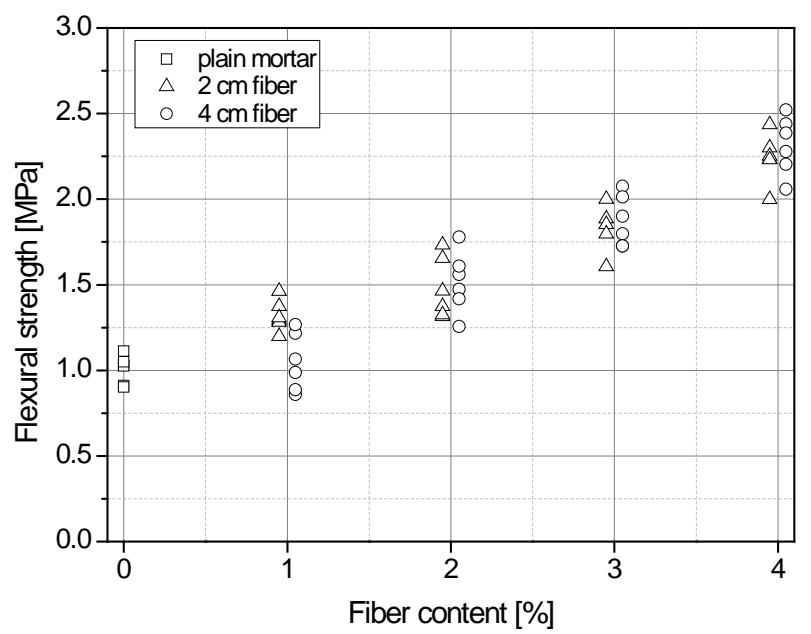

Figure 6: Flexural strength ( $\left.\sigma_{\mathrm{b} 14}\right)$ at 14 days. $2 \mathrm{~cm}$ fiber $v s 4 \mathrm{~cm}$ fiber

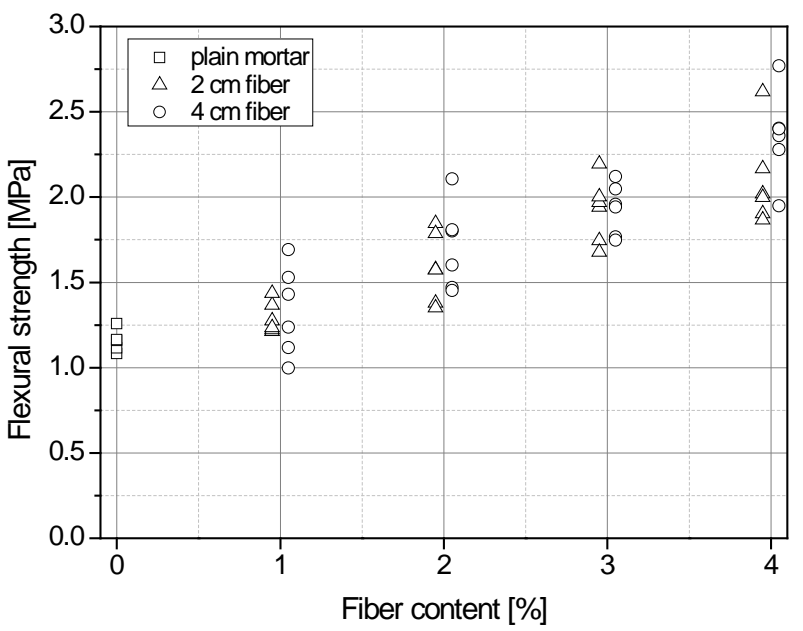

Figure 7: Flexural strength ( $\left.\sigma_{\mathrm{b} 28}\right)$ at 28 days. $2 \mathrm{~cm}$ fiber vs $4 \mathrm{~cm}$ fiber.

In order to complement this analysis, Table 2 summarizes the above data and presents 


\begin{tabular}{|c|c|c|c|c|}
\cline { 2 - 5 } \multicolumn{1}{c|}{} & \multicolumn{4}{|c|}{ бb28 (MPa) } \\
\hline \multirow{2}{*}{ Fiber content (\%) } & Sisal [15] & Acrylic [13] & $70 \%$ cotton and 30\% acrylic thread \\
\cline { 2 - 5 } & $\mathrm{L}=25 \mathrm{~mm}$ & $\mathrm{~L}=35 \mathrm{~mm}$ & $\mathrm{~L}=20 \mathrm{~mm}$ & $\mathrm{~L}=40 \mathrm{~mm}$ \\
\hline 0 & 1,02 & 1,03 & 1,17 & 1,17 \\
\hline 1 & 1,26 & 1,23 & 1,29 & 1,33 \\
\hline 4 & 2,01 & - & 2,10 & 2,36 \\
\hline
\end{tabular}

similar values obtained in other research works done on the same subject but concerning sisal [15] and acrylic [13] fibers. Apart from the differences in terms of fiber type, fiber length $(\mathrm{L})$ and nature of cement and aggregate used, all the results match the above conclusions.

Table 2: $\sigma \mathrm{b} 28$ of some cement based coating mortars reinforced with different types of fibers
250

251

252

\section{3 - Compressive test}

Similarly, a compressive test was also performed. In this context, the obtained experimental results converge to the same conclusions identified in Section 5.2. The quantified average compression stress $\left(\sigma_{c}\right)$, for each case and for the ages of 14 days ( $\left.\sigma_{c 14}\right)$ and 28 days $\left(\sigma_{c 28}\right)$, is presented in Table 3.

Table 3: Results of the compression test

\begin{tabular}{|c|c|c|}
\hline Case & $\sigma_{\mathrm{c} 14}(\mathrm{MPa})$ & $\sigma_{\mathrm{c} 28}(\mathrm{MPa})$ \\
\hline 1 & 3,96 & 4,37 \\
\hline 2 & 4,21 & 4,58 \\
\hline 3 & 4,71 & 5,14 \\
\hline 4 & 6,20 & 5,90 \\
\hline 5 & 6,93 & 6,78 \\
\hline 6 & 3,76 & 3,80 \\
\hline 7 & 4,99 & 5,16 \\
\hline 8 & 6,64 & 6,26 \\
\hline 9 & 6,98 & 6,82 \\
\hline
\end{tabular}

257 Meanwhile, Table 4 gives additional information related to the compressive strength obtained in other reinforced cement based coating mortar contexts (e.g. sisal and acrylic fiber types). In terms of compressive strength, there is a high variability in terms of this mechanical property among the considered reinforced solutions. Taking into account the 
differences indicated in Section 5.2 and the data of Table 4, a compressive strength decreasing for the sisal [15] and the acrylic [13] fiber solutions when the fiber content increases is featured. In contrast, in the $70 \%$ cotton and $30 \%$ acrylic thread fiber solution an opposite behavior seems to occur. In this case, the compressive strength increases according to the increase of the fiber content. The different water absorption ability of each considered fiber type may justify this mechanical behaviour discrepancy.

Table 4: $\sigma_{\mathrm{c} 28}$ of some cement based coating mortars reinforced with different types of fibers

\begin{tabular}{|c|c|c|c|c|}
\cline { 2 - 5 } \multicolumn{1}{c|}{} & \multicolumn{4}{|c|}{$\sigma_{\mathrm{c} 28}(\mathrm{MPa})$} \\
\hline \multirow{2}{*}{ Fiber content (\%) } & Sisal [15] & Acrylic [13] & $70 \%$ cotton and 30\% acrylic thread \\
\cline { 2 - 5 } & $\mathrm{L}=25 \mathrm{~mm}$ & $\mathrm{~L}=35 \mathrm{~mm}$ & $\mathrm{~L}=20 \mathrm{~mm}$ & $\mathrm{~L}=40 \mathrm{~mm}$ \\
\hline 0 & 7,57 & 5,69 & 4,37 & 4,37 \\
\hline 1 & 7,03 & 5,44 & 4,58 & 3,80 \\
\hline 4 & 5,41 & - & 6,78 & 6,82 \\
\hline
\end{tabular}

\section{6 - APPLICABILITY AND MATERIAL COMPACTIBILITY}

As it was mentioned in Section 4.2, in an early stage of this research, a preliminary experimental procedure was done to verify the applicability of the proposed reinforced solution. In order to complement this analysis the fiber dispersion, the material adherence and the fiber failure mode were additional technical aspects taken into consideration. Thus, the sample bending rupture surfaces were carefully analyzed in order to find evidence related to these aspects that may influence the workability of the material.

In Figure 8, those surfaces are presented for the cement based coating mortar samples reinforced with $2 \mathrm{~cm}$ fiber and for the different fiber contents. Acceptable uniform fiber dispersion seems to be achieved. A similar conclusion was obtained for the samples reinforced with $4 \mathrm{~cm}$ fiber. 


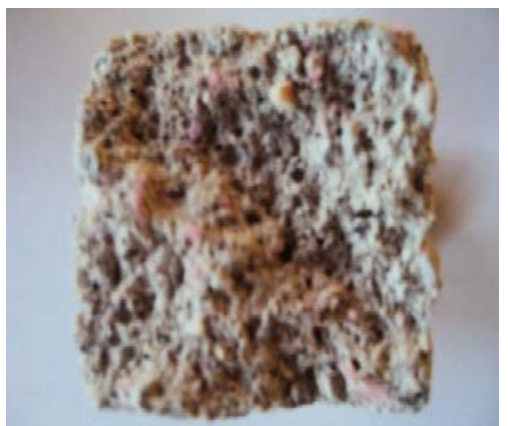

a) $1 \%$

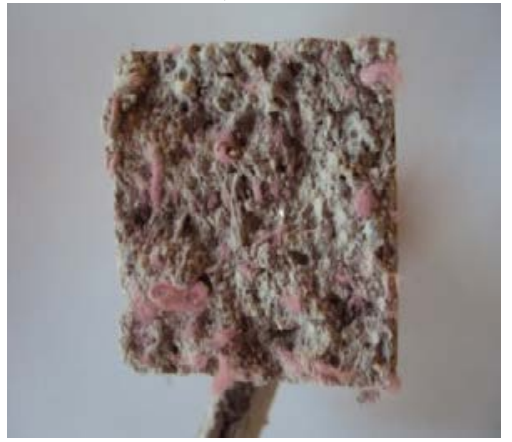

c) $3 \%$

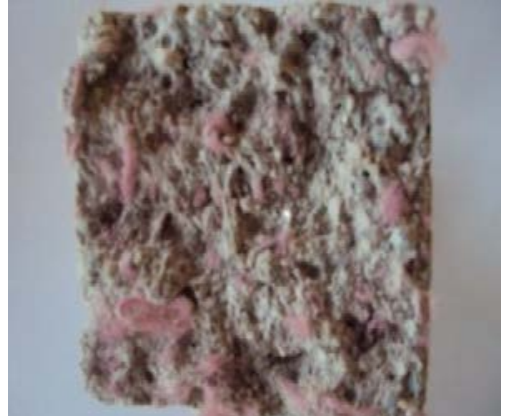

b) $2 \%$

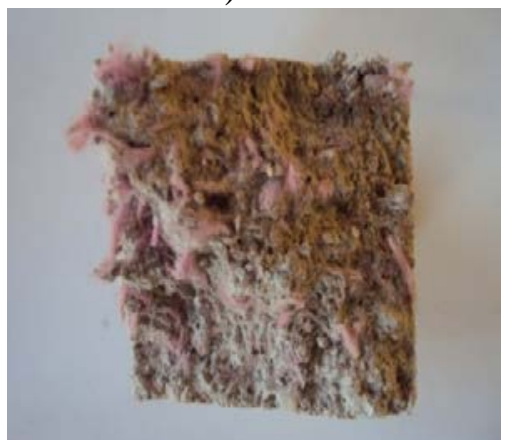

d) $4 \%$

The same surfaces made it possible to obtain evidence about aspects related to material adherence and fiber failure mode. These two technical aspects are fundamental in a composite material. In this respect, amplified pictures of the mortar fracture surfaces were specifically prepared in order to focus in the bond between fiber and mortar. These pictures are shown in Figure 9 and for the different fiber contents. On the other hand, these pictures also allow figuring out the fiber failure mode in the bending tests. This fiber failure mode is characterized by the cut of the fiber followed by an unrolling of the micro threads (III, Figure 9). These observations may indicate that the adopted thread length (2 and $4 \mathrm{~cm}$ ) is higher than the critical embedment length, favoring the fiber rupture occurrence. However this failure mode is undesirable, since it will lead to less ductile behavior of the composite.
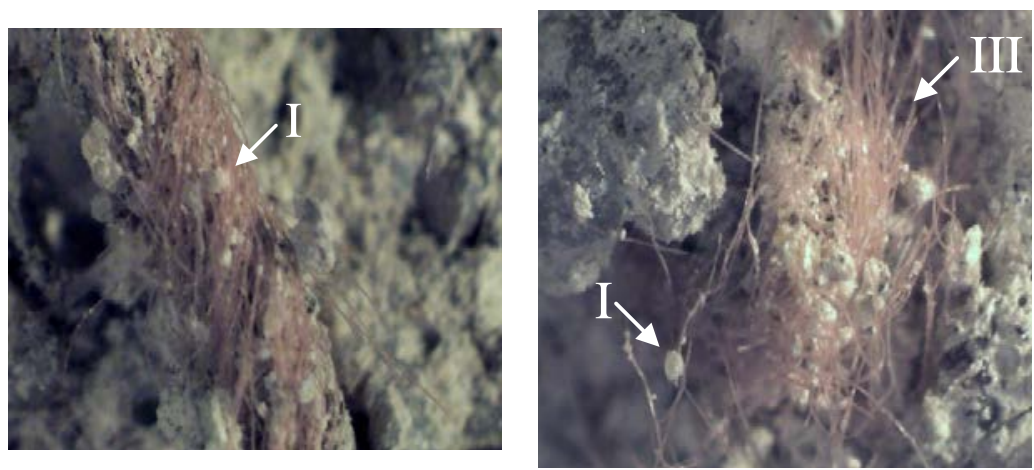
a) $1 \%$

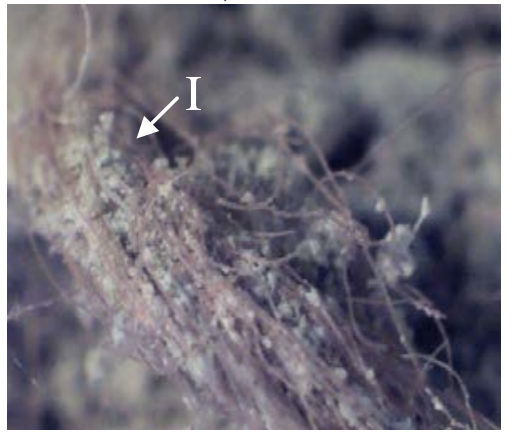

c) $3 \%$ b) $2 \%$

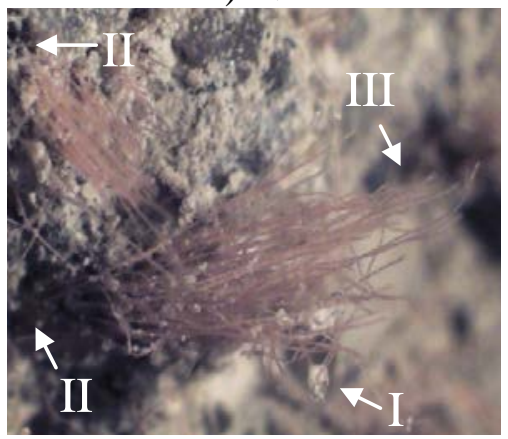

d) $4 \%$

Figure 9: Amplified pictures of the connection between fiber and mortar after failure

\section{7 - FINAL REMARKS}

An alternative cement based coating mortar reinforcement technique was proposed based on the incorporation of textile threads. This building solution may be interesting from a sustainable point of view because the thread may be a textile industry waste. Taking into account the expressive material variability of that waste, a $70 \%$ cotton and a $30 \%$ acrylic composition thread was selected as the fiber considered in this research. Therefore, it was necessary to perform a material characterization of the fiber. As a result, it was concluded that this type of fiber has an approximate $1 \mathrm{~mm}$ diameter and it is formed by a set of micro threads rolled to each other. It has an elastic behaviour, and an approximate tensile strength and modulus of elasticity of 7.44 MPa and 24.40 MPa, respectively. Fiber length and fiber content were two technical aspects considered relevant and thus analyzed in detail. Consequently, an exhaustive parametric study was done in which nine different compositions of reinforced coating mortar were defined. Meanwhile, a preliminary experimental procedure allowed the verification of the fact that the proposed building solution has adequate workability and durability. Bending and compressive tests also led to the conclusion that the mechanical behavior of the coating mortar may increase according to the increase of the fiber content. In contrast, this tendency does not seem to occur when the fiber length increases. Additionally, high fiber lengths may reduce the workability of the mortar. Moreover, it was noticed that it is possible to obtain adequate uniform fiber dispersion, and that there is an adequate bond between the fiber and the mortar. These two technical aspects are relevant in a composite material (e.g. reinforced coating mortar), in particular, the material 
compatibility. In a practical building scenario, a mixture of different types of threads as a waste product resulting from the textile industry is expected to occur. Therefore, further research is required to be done on this subject. Furthermore, the experimental results obtained may give guidelines for other possible applications of textile thread as a reinforcement fiber for other building elements with non-structural purposes.

\section{ACKNOWLEDGEMENT}

The authors express their sincere gratitude to FCT, project PEst-C/CTM/LA0025/2011, for the given financial support. A special thanks to Textâmega, Supercorte and Profato companies.

\section{BIBLIOGRAPHY REFERENCES}

[1] J. Younquist, B. English, H. Spelter, P. Chow, Agricultural fibers in composition panels, Proceedings of the 27th International particleboard/composite materials symposium, 1993 March 30-31, Pullman, WA. Pullman, WA: Washington Sate University, 1993: 133-152.

[2] A. Paiva, S. Pereira, A. Sá, D. Cruz, H. Varum, J. Pinto, A contribution to the thermal insulation performance characterization of corn cob particleboards, Energy and Buildings (2010), doi:10.1016/j.enbuild.2011.11.019.

[3] D.A. Adesanya, A.A. Raheem, Development of corn cob ash blended cement, Construction and Building Materials:23 (2009) 347-352

[4] S. Panthapulakkal, M. Sain (2007). Agro-residue reinforced high-density polyethylene composites: Fiber characterization and analysis of composite properties. Composites: Part A 38. pp. 1445-1454.

[5] N. Soon-Ching, L. Kaw-Sai (2010). Thermal conductivity of newspaper sandwiched aerated lightweight concrete panel. Energy and Buildings 42. pp. 2452-2456. 
349 [6] P. Lertsutthiwong, S. Khunthon, K. Siralertmukul, K. Noomun, S. Chandrkrachang, 350 New insulating particleboards prepared from mixture of solid wastes from tissue paper manufacturing and corn peel, Bioresource Technology 99 (2008) 4841-4845.

[7] M.A.S. Mohamed, E. Ghorbel, G. Wardeh (2010). Valorization of micro-cellulose fibers in self-compacting concrete, Construction and Building Materials, 24: 2473-2480.

[8] P. Marques, Raúl Fangueiro, C. Gonilho Pereira (2010). Directionally oriented

fibrous structures for lightweight concrete elements reinforcement,in Structures and Architecture, eds. Cruz et al., pp. 1642-1649.

[9] Paiva, A.; Varum, H.; Caldeira, F.; Sá, A.; Nascimento, D.; Teixeira, N. (2011) -

Textile subwaste as a thermal insulation building material - 2011 International

Conference on Petroleum and Sustainable Development (ICPSD 2011) - International Proceedings of Chemical, Biological \& Environmental Engineering (IPCEEE), ISSN 2010-4618, ISBN 978-981-07-1054-5, Edited by Yang Dan, IACSIT Press, Singapore, Vol. 26, pp. 78-82 - Dubai, UAE, December 2011.

[10] H. Savastano, V. Agopyan, U Adrian, M. Nolasco, L. Pimentel (1999) Plant fibre reinforced cement components for roofing, Construction and Building Materials, 13: 433-438.

[11] F.A. Silva, R. D. Toledo Filho, J.A.Melo Filho, E.M.R. Fairbairn (2010),Physical and mechanical properties of durable sisal fiber-cement composites, Construction and Building Materials, 24: 777-785.

[12] A. Elsaid, M. Dawood, R. Seracino, C. Bobko (2011). Mechanical properties of 
acrylic fibers). Proceedings of the $2^{\circ}$ Congresso Nacional de Argamassas de Construção. APFAC. Lisboa. Portugal. [in Portuguese].

382

[14] Luiz Oliveira, Paula Alves, Sérgio Dias (2010). Desempenho de argamassas de revestimento com incorporação de fibras de plásticos reciclados (Performance of cement based coating mortars reinforced with recycled plastic fibers). Proceedings of

386 the $3^{\circ}$ Congresso Português de Argamassas de Construção. APFAC. Lisboa. Portugal. 387 [in Portuguese].

389 [15] Luís Dias, Anabela Paiva, José Vieira (2010). Reforço de rebocos com fibras de 390 sisal (Cement based coating mortars reinforced with sisal fibres) Proceedings of the $3^{\circ}$ 391 Congresso Português de Argamassas de Construção. APFAC. Lisboa. Portugal. [in 392 Portuguese].

394 [16] EN 1015-11 - "Methods of test for mortar for masonry Part 1: Determination of 395 flexural and compressive strength of hardened mortar”, 1999.

397 [17] EN 988-1 - "Specifications for mortar for masonry Part 1: Rendering and 398 plastering mortar”, April 2003. 